\title{
The Role of Absorptive Capacity in Acquisition Knowledge Transfer.
}

By: Paulina Junni and Riikka M. Sarala

Junni, P. \& Sarala, R.M. (July 1, 2013). The Role of Absorptive Capacity in Acquisition Knowledge Transfer. Thunderbird International Business Review, 55(4), 419-438.

The definitive version is available at http://onlinelibrary.wiley.com/doi/10.1002/tie.21554/full.

***Reprinted with permission. No further reproduction is authorized without written permission from Wiley-Blackwell. This version of the document is not the version of record. Figures and/or pictures may be missing from this format of the document. ***

\begin{abstract}
:
This article examines the role of absorptive capacity in acquisitions. We propose that absorptive capacity is an important determinant of acquisition knowledge transfer. Also, we identify antecedents of absorptive capacity in the specific context of acquisitions. These include contextual (national cultural differences), individual (employee withdrawal), and organizational design level (integration process communication, knowledge processing system) antecedents. We test our hypotheses on a sample of domestic and foreign acquisitions conducted by Finnish companies. This study contributes to the acquisition literature by elaborating on the role of absorptive capacity in acquisitions and to the general absorptive capacity literature by highlighting the importance of previously underexplored antecedents and outcomes of absorptive capacity.
\end{abstract}

Keywords: knowledge transfer | business acquisitions | business management | Finland

Article:

Introduction

Acquisitions are among the most popular growth and internationalization strategies for firms (Boateng, Qian, \& Tianle, 2008; Lynch, 2006). However, regardless of their prevalence, acquisitions often fall short of expectations (King, Dalton, Daily, \& Covin, 2004). To explain this, previous acquisition research has focused mostly on examining the influence of financial and strategic factors at the preacquisition stage, such as relatedness of the firms, method of payment, and prior acquisition experience (King et al., 2004). However, these factors only partially explain acquisition outcomes, suggesting the need for additional theory development (Gomes, Angwin, Weber, \& Tarba, in press; King et al., 2004; Stahl \& Voigt, 2008).

Specifically, further research on sociocultural and organizational aspects in acquisitions has been called for in order to understand how people, culture, and organizational processes contribute to acquisition outcomes (Haspeslagh \& Jemison, 1991; Ivancevich, Schweiger, \& Power, 1987; 
Nahavandi \& Malekzadeh, 1988; Weber \& Fried, 2011; Weber \& Tarba, 2010). Within this perspective, researchers have examined the effect of cultural differences on acquisition outcomes. While a lack of cultural or social "fit" has been argued to derail acquisitions in general (Buono \& Bowditch, 1989; Datta \& Puia, 1995; Nahavandi \& Malekzadeh, 1988; Weber, 1996), there is also evidence that particularly national cultural differences could have positive effects (Morosini, Shane, \& Singh, 1998; Sarala \& Vaara, 2010; Vaara, Sarala, Stahl, \& Björkman, 2012) or the effect could be moderated by the integration approach (Weber, Tarba, \& Reichel, 2009). Another popular stream has been to focus on examining various negative employee reactions resulting from an acquisition - such as anxiety, uncertainty, stress, cooperation problems, social conflict, and power games (Ivancevich et al., 1987; Schmid \& Daniel, 2009; Vaara et al., 2012; Van Dick, Ullrich, \& Tissington, 2006). Furthermore, the acculturation perspective has proposed target firm sociocultural characteristics, such as cultural preservation and negative perceptions of the partner, as further impediments in acquisitions (Nahavandi \& Malekzadeh, 1988; Sarala, 2010). Finally, inspired by the process perspective of Haspeslagh and Jemison (1991), researchers have taken a comprehensive view of the acquisition process (e.g., Calipha, Tarba, \& Brock, 2010; Weber \& Tarba, 2012) or focused on the impact of specific organizational processes and managerial actions, such as communication (Birkinshaw, Bresman, \& Håkanson, 2000; Buono \& Bowditch, 1989; Weber \& Tarba, 2010), integration approach (Ellis, Weber, Raveh, \& Tarba, 2012; Tarba, Almor, \& Benyamini, 2012; Weber \& Tarba, 2011; Weber, Tarba, \& Reichel, 2011; Weber, Tarba, \& Rozen-Bachar, 2011; Weber, Tarba, Stahl, \& Rozen-Bachar, 2013), cultural integration (Junni \& Sarala, 2011; Sarala \& Vaara, 2010), cultural learning and collective teaching (Junni \& Sarala, 2012) and autonomy (Almor, Tarba, \& Benjamini, 2009; Hambrick \& Cannella, 1993; Ranft \& Lord, 2000).

However, the role of absorptive capacity in acquisitions remains relatively unexplored (for notable exceptions, see Ahuja \& Katila, 2001; Björkman, Stahl, \& Vaara, 2007; Deng, 2010). This is surprising because absorptive capacity is one of the most important determinants of knowledge and innovation processes because it defines the level to which the firm can obtain external knowledge from its environment (cf. Volberda, Foss, \& Lyles, 2010). Absorptive capacity is likely to be highly relevant in acquisitions because acquisitions are amongst the primary vehicles for obtaining external knowledge (Haspeslagh \& Jemison, 1991). Yet, our understanding of both how absorptive capacity contributes to important acquisition outcomes and how absorptive capacity is influenced by sociocultural and organizational processes remains incomplete.

Based on Zahra and George (2002), we understand absorptive capacity as a dynamic capability that impacts the firm's competitive advantage. We propose that absorptive capacity is a dynamic organizational-level capability that essentially resides within the employees of the organization 
(Björkman et al., 2007; Empson, 2001; Minbaeva, 2007; Minbaeva, Pedersen, Björkman, Fey, \& Park, 2003; Szulanski, 1996; Szulanski, Cappetta, \& Jensen, 2004). Absorptive capacity of the firm consists of the ability and motivation of the organizational members to access and make use of external knowledge (Minbaeva, 2007; Minbaeva et al., 2003). Ability refers to the knowledge bases of organizational members (e.g., skills, competences, and educational background) and reflects the employees' prior related knowledge (Minbaeva, 2007; Minbaeva et al., 2003; Szulanski, 1996; Szulanski et al., 2004). Motivation refers to the intensity of effort that organizational members are willing to exert towards absorbing external knowledge (Minbaeva et al., 2003; Minbaeva, 2007). Applying this definition to the context of acquisitions, the acquiring firm's absorptive capacity consists of acquiring firm members' ability and motivation to absorb the target's knowledge whereas the target firm's absorptive capacity consists of the target firm members' ability and motivation to absorb the acquirer's knowledge.

Understanding absorptive capacity as a dynamic capability means that it can have various antecedents and outcomes and can be influenced by organizational processes and managerial actions (Zahra \& George, 2002). However, recent theoretical reviews of the absorptive capacity literature indicate important limitations in our understanding of these antecedents and outcomes (Todorova \& Durisin, 2007; Volberda et al., 2010). Especially, Volberda et al. (2010) argue that "we need to know more of the specific outcomes and payoffs of absorptive capacity" (p. 942) related to intangible outcomes, such as knowledge transfer. In this study, we focus on knowledge transfer as an intangible outcome of absorptive capacity. We define knowledge transfer as the use of the partner's knowledge by the recipient (Minbaeva et al., 2003). Knowledge transfer is of utmost importance in acquisitions. Haspeslagh and Jemison (1991) argue that "acquisitions create value when the competitive advantage of one firm is improved through the transfer of strategic capabilities" (p. 28). More specifically, acquiring firms can access unique and valuable knowledge from the target in order to complement their existing knowledge bases (Deng, 2010; Westphal \& Shaw, 2005). In addition, acquirers can seek to improve the target's performance by transferring their best practices to the target (Haspeslagh \& Jemison, 1991). Zollo and Meier (2008) argue that knowledge transfer is one of the task-level acquisition performance measures, which influences overall acquisition performance both directly and through its effect on other aspects of performance. Also, Ahammad and Glaister (2011) empirically link knowledge transfer to improved performance in foreign acquisitions.

Concerning the antecedents of absorptive capacity, Volberda et al. (2010) maintain that studies that consider contextual antecedents are underrepresented in the field with more work needed on examining the effect of different environmental conditions. In the acquisition context, national cultural differences are among the key contextual variables (Datta, 1991; Olie, 1994; Weber, Shenkar, \& Raveh, 1996). In addition, individual level antecedents of absorptive capacity have 
been relatively neglected resulting in little knowledge on the effect of employee related issues, such as personnel turnover, on absorptive capacity (Volberda et al., 2010). However, turnover and other forms of employee withdrawal are common in acquisitions (Fried, Tiegs, Naughton, \& Ashforth, 1996; Weber, Rachman-Moore, \& Tarba, 2011; Weber et al., 1996, Weber, Tarba, \& Bachar, 2012), which makes it particularly vital to understand whether such negative employee reactions may be detrimental to absorptive capacity in acquisitions. Furthermore, even though the original study of Cohen and Levinthal (1990) points to the importance of "distinctly organizational aspects," subsequent research has largely ignored the role of organizational design antecedents in defining absorptive capacity (Lane, Koka, \& Pathak, 2006; Volberda et al., 2010), such as the roles of control, coordination, and communication systems. In the acquisition context, it is increasingly accepted that organizational design factors, including the management of the integration process, play an important role (Gomes, Weber, Brown, \& Tarba, 2011; Haspeslagh \& Jemison, 1991; Weber \& Tarba, 2010), but our understanding of how organizational aspects, such as integration process communication and knowledge processing system, can promote absorptive capacity remains unexplored.

Therefore, the aim of this article is to develop and test a model on the role of absorptive capacity in acquisitions by combining key topics in acquisition and absorptive capacity literatures. We examine the influence of absorptive capacity on intangible acquisition outcomes (knowledge transfer) and identify the effects of contextual antecedents (national cultural differences), individual antecedents (employee withdrawal), and organizational design antecedents (integration process communication, knowledge processing system) on absorptive capacity. To address the paucity of empirical studies that examine the role of absorptive capacity in acquisitions, we test our model in the context of domestic and foreign acquisitions conducted by Finnish firms.

\section{Theoretical Background}

\section{The Theory of Absorptive Capacity}

Absorptive capacity was described by Cohen and Levinthal (1990) as a firm's ability to recognize, value, assimilate, and apply new external knowledge to benefit the firm. Since then, absorptive capacity has become one of the most influential concepts in contemporary management literature (for reviews of absorptive capacity literature, see Lane et al., 2006; Volberda et al., 2010; Zahra \& George, 2002). Cohen and Levinthal (1990) proposed that absorptive capacity is largely a "function of the firm's level of prior related knowledge" (p. 128). They argued that "accumulated prior knowledge increases both the ability to put new knowledge 
into memory" (p. 129), and "the ability to recall and use it" (p. 129). This has led to many subsequent studies to include prior knowledge as a part of their conceptualization of absorptive capacity (e.g. Björkman et al., 2007; Deng, 2010; Minbaeva et al., 2003; Mowery, Oxley, \& Silverman, 1996; Szulanski, 1996).

Cohen and Levinthal (1990) further suggested that prior related knowledge can be measured as the firm's research and development (R\&D) intensity and several later studies have followed this approach (Mowery et al., 1996; Nicholls-Nixon \& Woo, 2003; Schildt, Keil, \& Maula, 2012; Tsai, 2001). Numerous studies have, however, criticized the conceptualization of absorptive capacity as R\&D specific and have claimed that it is too narrow. More specifically, several studies argue that absorptive capacity, although an organizational-level construct, essentially resides within the employees of the organization (Björkman et al., 2007; Empson, 2001; Minbaeva, 2007; Minbaeva et al., 2003; Szulanski, 1996; Szulanski et al., 2004). These studies maintain that prior knowledge does not equal R\&D, but should be understood as the combined ability of organizational members in terms of the knowledge bases that they possess, including employee skills, competences, and educational backgrounds (Minbaeva, 2007; Minbaeva et al., 2003; Szulanski, 1996; Szulanski et al., 2004).

In addition to prior knowledge, Cohen and Levinthal (1990) mention that absorptive capacity depends on the intensity of effort (Cohen \& Levinthal, 1990). Subsequent studies have developed this argument further. Particularly, Minbaeva (2007) and Minbaeva et al. (2003) argue that absorptive capacity, in addition to prior knowledge, encompasses the motivation of organizational members, which relates to their intensity of effort to absorb the partner's knowledge (Minbaeva, 2007; Minbaeva et al., 2003). Accordingly, Minbaeva et al. (2003) found that both employee ability (which they argue reflects prior knowledge) and motivation must be present to achieve a higher degree of knowledge transfer in MNCs.

Furthermore, Cohen and Levinthal (1990) argued that "it is useful to consider what aspects of absorptive capacity are distinctly organizational" (p. 131). For instance, they discuss the role of communication systems, organizational structure, and cross-functional interfaces in relation to absorptive capacity. To explore these and other organizational design aspects further, researchers have examined the influence of organizational form and have found that cross-functional ties, job rotation, and social connectedness increase absorptive capacity (Jansen, Van den Bosch, \& Volberda, 2005). Also, Khoja and Maranville (2010) established that another aspect of organizational design, organizational culture, impacts the absorptive capacity of firms. Finally, Minbaeva et al. (2003) found that the firm's human resource system can enhance the absorptive capacity of organizational units in MNCs. While these studies have shed some light on how 
organizational factors can impact absorptive capacity, several studies have called for more research on organizational determinants of absorptive capacity (Jansen et al., 2005; Lane et al., 2006; Minbaeva et al., 2003; Van den Bosch, Volberda, \& De Boer, 1999; Volberda et al., 2010).

Finally, prior research suggests that absorptive capacity may be influenced by contextual factors. Mostly, the focus has been on the industry level. Cohen and Levinthal (1990) discussed industry demand, appropriability, and technological opportunity. Similarly, Jansen et al. (2005) and Van den Bosch et al. (1999) considered industry competitiveness and dynamism. However, country level factors have also been discussed in connection to absorptive capacity as contextual factors, although they remain much less explored than industry-level factors. For instance, Mowery, Oxley and Silverman (1996) found that nations that invest in scientific and technical training and economic policies that enforce competition increase their national absorptive capacity, which results in higher national innovation and productivity. Similarly, Keller (1996) observed that national absorptive capacity allows better exploitation of technology. Finally, Kedia and Bhagat (1988) proposed that differences in societal cultures can explain the level of absorptive capacity.

Absorptive capacity was initially researched in intra-organizational contexts (e.g., Cohen \& Levinthal, 1990; Nicholls-Nixon \& Woo, 2003). However, it has also been explored in interorganizational contexts: in different MNC units (e.g., Jansen et al., 2005; Minbaeva et al., 2003; Szulanski, 1996) and in alliances (e.g., Lane \& Lubatkin, 1998; Mowery et al., 1996). Only a few studies have examined absorptive capacity in the context of acquisitions. Björkman et al. (2007) suggest a mediating influence of absorptive capacity, but do not provide an empirical test for any of their propositions. Ahuja and Katila (2001) quantitatively examine the relationship between absorptive capacity and innovation. However, their conceptualization of absorptive capacity is limited because it considers only the firm's existing knowledge bases without considering the broader organizational context of absorptive capacity. Finally, in a small case study, Deng (2010) found that absorptive capacity was an important determinant of Chinese acquirers' ability to obtain strategic assets and achieve superior business performance. Yet, this approach is limited in its ability to provide generalizations beyond specific cases, and the study also did not consider absorptive capacity of the target firm. Thus, while these prior studies point to the importance of absorptive capacity in acquisitions, it is clear that much more work is needed for a more comprehensive understanding of the role of absorptive capacity in this context.

In conclusion, although many studies in the absorptive capacity literature equal absorptive capacity with the firm's prior knowledge/R\&D spending, other studies point to a broader conceptualization of absorptive capacity as being determined by several factors. In this article, 
we define absorptive capacity as a capability that consists of the ability and motivation of organizational members to absorb knowledge (Björkman et al., 2007; Minbaeva, 2007; Minbaeva et al., 2003). Further, we argue that absorptive capacity (employee ability and motivation) is influenced by a broad range of antecedents, as reflected in our review of literature. In the following, we will focus on examining the relationship between absorptive capacity and acquisition knowledge transfer. In addition, we will focus on examining those antecedents that prior reviews of absorptive capacity argue to be underrepresented (Volberda et al., 2010), and that we consider central for acquisition integration based on prior acquisition research.

Hypotheses

Absorptive Capacity and Acquisition Knowledge Transfer

Knowledge transfer is conceptualized as the use of the partner's knowledge by the recipient (Minbaeva et al., 2003) and consists of knowledge flows in different directions (Gupta \& Govindarajan, 2000). In the acquisition context, knowledge transfer involves knowledge flows in either or both of the following directions: from the acquiring firm to the target; from the target firm to the acquirer (Bresman, Birkinshaw, \& Nobel, 1999). There is a growing body of research that aims to explain knowledge transfer in the context of acquisitions. Most studies have focused on knowledge characteristics, such as tacitness (Bresman et al., 1999; Junni, 2011; Westphal \& Shaw, 2005), ambiguity (Junni \& Sarala, 2011), and social embeddedness (Ranft and Lord, 2002). Also, characteristics of the sending and receiving firms, such as the relative size and relatedness of the knowledge bases (Ahuja \& Katila, 2001; Capron, Dussauge, \& Mitchell, 1998; Westphal \& Shaw, 2005), have been examined. Fewer studies have addressed how sociocultural aspects impact knowledge transfer in acquisitions (Empson, 2001; Junni, 2011, Junni \& Sarala, 2011; Junni \& Sarala, 2012; Sarala \& Vaara, 2010; Vaara et al., 2012). Furthermore, researchers have called for studies that elaborate on the role of absorptive capacity in acquisitions (Björkman et al., 2007).

As discussed in the previous section, our definition of absorptive capacity entails organizational members' ability and motivation to take up and make use of new knowledge (Minbaeva, 2007; Minbaeva et al., 2003). The ability dimension of absorptive capacity relates to the knowledge bases of organizational members (e.g., their skills, competencies, and educational backgrounds), reflecting employees' prior related knowledge that allows them to understand and utilize the partner's knowledge (Minbaeva, 2007; Minbaeva et al., 2003; Szulanski, 1996). In turn, the motivation dimension concerns how much energy and effort organizational members are willing to put into learning from the partner in order to make use of its knowledge (Minbaeva, 2007; 
Minbaeva et al., 2003; Szulanski, 1996). Both the ability and motivation of the recipient to absorb knowledge are necessary for knowledge transfer (Minbaeva, 2007; Minbaeva et al. 2003).

Previous research has considered absorptive capacity as one of the most central determinant of knowledge transfer. A meta-analysis of knowledge transfer studies found strong support for absorptive capacity as a facilitator of knowledge transfer (Van Wijk, Jansen, \& Lyles, 2008). This reflects findings of individual studies that have linked absorptive capacity to learning and knowledge transfer in alliances (Mowery et al., 1996) and MNCs (Gupta \& Govindarajan, 2000; Minbaeva, 2007; Minbaeva et al., 2003). In the acquisition context, in their theoretical paper, Björkman et al. (2007) propose a theoretical link between potential absorptive capacity and realized knowledge transfer. More specifically, and similar to Minbaeva (2007) and Minbaeva et al. (2003), Björkman et al. (2007) argue that members of the receiving firm need to be able to understand the sender's knowledge and how it can be applied in the receiving firm's context to have the potential to make use of it. However, to exploit this potential, they also need to be motivated to learn and to make use of the knowledge for successful knowledge transfer to take place. Based on these arguments, we suggest that:

Hypothesis 1: The absorptive capacities of the acquiring and target firms are positively related to knowledge transfer from the acquirer to the target and from the target to the acquirer respectively.

We will now move on to discuss the antecedents of absorptive capacity in acquisitions.

Antecedents of Absorptive Capacity in Acquisitions

National cultural differences can be defined as differences in the way in which a group of people solves problems and reconciles dilemmas across different national societies (Hofstede, 1991; Trompenaars \& Hampden-Turner, 1997). People in the same national culture are more likely to have analogous cognitive models of making sense of the world (Hofstede, 1991). Based on absorptive capacity literature, contextual similarity facilitates organizational members' cognitive "ease" of knowledge absorption because it allows for recognizing and understanding not only the partner's knowledge, but also the context in which such knowledge resides, and the assumptions that shape it (Lane \& Lubatkin, 1998; Simonin, 1999). This is particularly important for absorbing knowledge that is ambiguous, tacit, and embedded - all characteristics that make knowledge valuable but "sticky" (Szulanski, 1996). Thus, national cultural similarity in domestic 
acquisitions is likely to improve target firm members' ability to absorb the acquirer's knowledge. This will be more difficult as national cultural differences increase in foreign acquisitions.

Also, to be motivated, organizational members need to be able to recognize the value of new knowledge residing in the partner firm. Similar cognitive models resulting from similar national cultures facilitate the understanding of the nature and purpose of the partner's knowledge, which increases the legitimacy of this knowledge (Kostova \& Roth, 2002). Also, similar cognitive models may reduce perceptions of knowledge ambiguity and make it easier for the acquisition partners to recognize the link between knowledge application and superior firm performance (Simonin, 1999). Finally, when the knowledge stems from a culturally close context and largely fits the existing cognitive schemas of the sender and the receiver, it can be incorporated into the receiver's cognitive structures without major alterations (Todorova \& Durisin, 2007), making knowledge absorption faster and easier than if it required substantial changes in the cognitive structures. Thus, similar to the theoretical proposition of Björkman et al. (2007), we suggest that:

Hypothesis 2: National cultural differences are negatively related to the absorptive capacities of the acquiring and the target firms.

Employee withdrawal refers to "different distancing behaviors and cognitions, ranging from intentions to quit to more subtle psychological neglect such as not fully concentrating on work" (Kiefer, 2005, p. 882). Thus, employee withdrawal encompasses not only employee turnover, but also other symptoms such as lack of motivation, increase in absenteeism, decrease in productivity and resistance to change (Beehr \& Gupta, 1978; Kiefer, 2005). Employee withdrawal is a particularly serious problem in acquisitions (e.g. Fried et al., 1996). It is triggered by organizational changes that threaten job security, identity, and status as a result of an acquisition (Cartwright \& Cooper, 1993; Kiefer, 2005). Prior studies have reported anxiety, uncertainty and stress (Ivancevich, Schweiger, \& Power, 1987), absenteeism (Davy, Kinicki \& Scheck, 1997), lack of motivation, change resistance (Bouwen \& Overlaet, 2001), social conflict (Sarala, 2010; Vaara et al., 2012), and turnover (Hambrick \& Cannella, 1993; Ranft \& Lord, 2002; Ahammad, Glaister, Weber, \& Tarba, 2012) as typical employee reactions to acquisitions. Target firm members commonly react more negatively to acquisitions than acquiring firm members because target firm employees struggle to maintain their identity (Terry \& Callan, 1998; Van Knippenberg, Van Knippenberg, Monden, \& de Lima, 2002) and are also more often subject to major personnel changes (Hambrick \& Cannella, 1993; Ranft \& Lord, 2002). However, some studies indicate that negative employee reactions also occur among acquiring firm members (Hogg \& Terry, 2001; Junni, 2011; Sarala, 2010). 
Because of a lack of research on individual antecedents on absorptive capacity (Volberda et al., 2010), prior research has not examined the link between employee withdrawal and absorptive capacity. However, we propose that employee withdrawal is likely to be extremely harmful for absorptive capacity. If organizational members physically disengage - temporarily through absenteeism or permanently by leaving the organization (Davy et al., 1997; Kiefer, 2005) — their individual skills are no longer available for the firm resulting in holes in the firm's overall knowledge base. The remaining firm members' ability and motivation to absorb new external knowledge is likely to be hampered because of the disruption in the social ties that link organizational members' capabilities to each other (Nahapiet \& Ghoshal, 1998) and because of the negative, demoralizing atmosphere that such actions create (Fried et al., 1996; Haspeslagh \& Jemison, 1991; Sagie, Birati, \& Tziner, 2002). Similarly, if organizational members psychologically disengage and withhold their effort (Sagie et al., 2002) or show active or passive change resistance (Bouwen \& Overlaet, 2001), their mental capacity and willingness to focus on knowledge absorption is likely to be reduced. We thus suggest that:

Hypothesis 3: Employee withdrawal in the acquiring and target firms is negatively related to the absorptive capacities of the respective organizations.

We define integration process communication as informing organizational members about the strategic and practical aspects of the integration process (Haspeslagh \& Jemison, 1991). An efficient integration process communication requires a large amount of information that is distributed effectively, honestly, and clearly (Birkinshaw et al., 2000; Gomes et al., 2011; Haspeslagh \& Jemison, 1991). It involves communicating about both the "past," in terms of each firm's history and the general values and beliefs that defined each organization, and about the "future," in terms of the vision and strategy of the combined organization, and the firms' roles in achieving the vision (Schweiger \& Goulet, 2005).

Although the link between integration process communication and absorptive capacity has not been examined in prior acquisition studies, and such organizational design antecedents remain rather unexplored even in the wider absorptive capacity literature, we do know from previous absorptive capacity studies that communication allows for more efficient processing of organizational knowledge (Gupta \& Govindarajan, 2000; Jansen et al., 2005; Nahapiet \& Ghoshal, 1998; Van den Bosch et al., 1999). In the specific context of the acquisition integration progress, communication provides organizational members with a better understanding of the integration process and clearer expectations concerning their roles vis-à-vis the partner 
(Birkinshaw et al., 2000). This reduces confusion about practical aspects, for instance, regarding possible changes in the tasks and responsibilities of organizational members (Buono \& Bowditch, 1989; Haspeslagh \& Jemison, 1991). In addition, communication about the strategic aspects of the acquisition, including the vision and strategy for the combined organization and the roles of the acquisition partners in this vision (Schweiger \& Goulet, 2005), is likely to be important for knowledge-related activities. Organizational members will be more motivated if they understand how absorbing the partner's knowledge is useful (Westphal \& Shaw, 2005) in terms of helping the combined organization achieve its vision and strategic goals. Organizational members may also be better able to identify the type of knowledge in the partner firm that has the most value for the combined organization when they understand the broader strategic aspects. Furthermore, communication that generates knowledge about the partners' contexts - such as their history and culture (Schweiger \& Goulet, 2005) — can facilitate knowledge absorption by allowing organizational members to see the path dependence and cultural contingency of the combined firm's knowledge. Finally, communication is likely to strengthen trust and social ties between the acquisition partners (Bresman et al., 1999). This may be a direct outcome of communication - more information increases familiarity and trust (Birkinshaw et al., 2000). Or it may be the consequence of the process of communication itself - for instance, face-to-face communication brings together organizational members and allows for more social interaction between them. Previous studies show that trust and social ties are important for increasing the motivation of organizational members to absorb knowledge by decreasing their psychological fears of being "contaminated" by the partner's knowledge (Empson, 2001; Junni, 2011). Accordingly, we propose that:

Hypothesis 4: Integration process communication is positively related to the absorptive capacities of the acquiring and the target firms.

To further address the paucity of research on organizational design antecedents of absorptive capacity (Lane et al., 2006; Volberda et al., 2010), in addition to integration process communication, we will also focus on the role of the firm's knowledge-processing system. A firm's knowledge-processing system can be broadly defined as an organizational platform that consists of elements related to the organization's structure, culture, practices and information systems, which collectively influence the firm's knowledge-related activities (Zhao \& Anand, 2009). We propose that a properly designed knowledge-processing system can facilitate absorptive capacity. A "flat," nonbureaucratic, and interconnected organizational structure creates an organizational environment that is more flexible (Van den Bosch et al., 1999; Zhao \& Anand, 2009). This contributes to a culture that is more open to change and new influences, which increases both the ability and motivation to absorb knowledge (Van den Bosch et al., 1999). A low level of centralization also allows for more lateral interaction between 
organizational members, which creates social ties that enhance the processing of collective knowledge (Gupta \& Govindarajan, 2000) and is thus likely to increase the ability and motivation of organizational members to absorb knowledge (Jansen et al., 2005). In addition, the firm's human resource system influences absorptive capacity by directly affecting organizational members' ability and motivation (Minbaeva et al., 2003). For instance, human resource practices, such as the use of cross-functional task forces (Gupta \& Govindarajan, 2000; Jansen et al., 2005) and team based appraisal and compensation systems (Zhao \& Anand, 2009), have been discussed in the literature in relation to increased absorptive capacity. Finally, Zhao and Anand (2009) emphasize the role of an information infrastructure in allowing employees to share knowledge. For instance, a well-designed intranet may function as an easily accessible depository of organizational knowledge that facilitates knowledge absorption. Thus, we propose that implementing this type of knowledge-processing system in the acquiring and target firms will significantly improve knowledge absorption. The importance of a knowledge-processing system has not previously been discussed in the acquisition literature, but some of the characteristics, such as low level of centralization (Ranft \& Lord, 2002) and sociocultural integration mechanisms (Björkman et al., 2007), have been suggested to promote knowledge related activities in acquisitions. This leads us to propose the following:

Hypothesis 5: An effective knowledge-processing system in the acquiring and the target firms is positively related to the absorptive capacities of the respective organizations.

The theoretical model is presented in Figure 1.

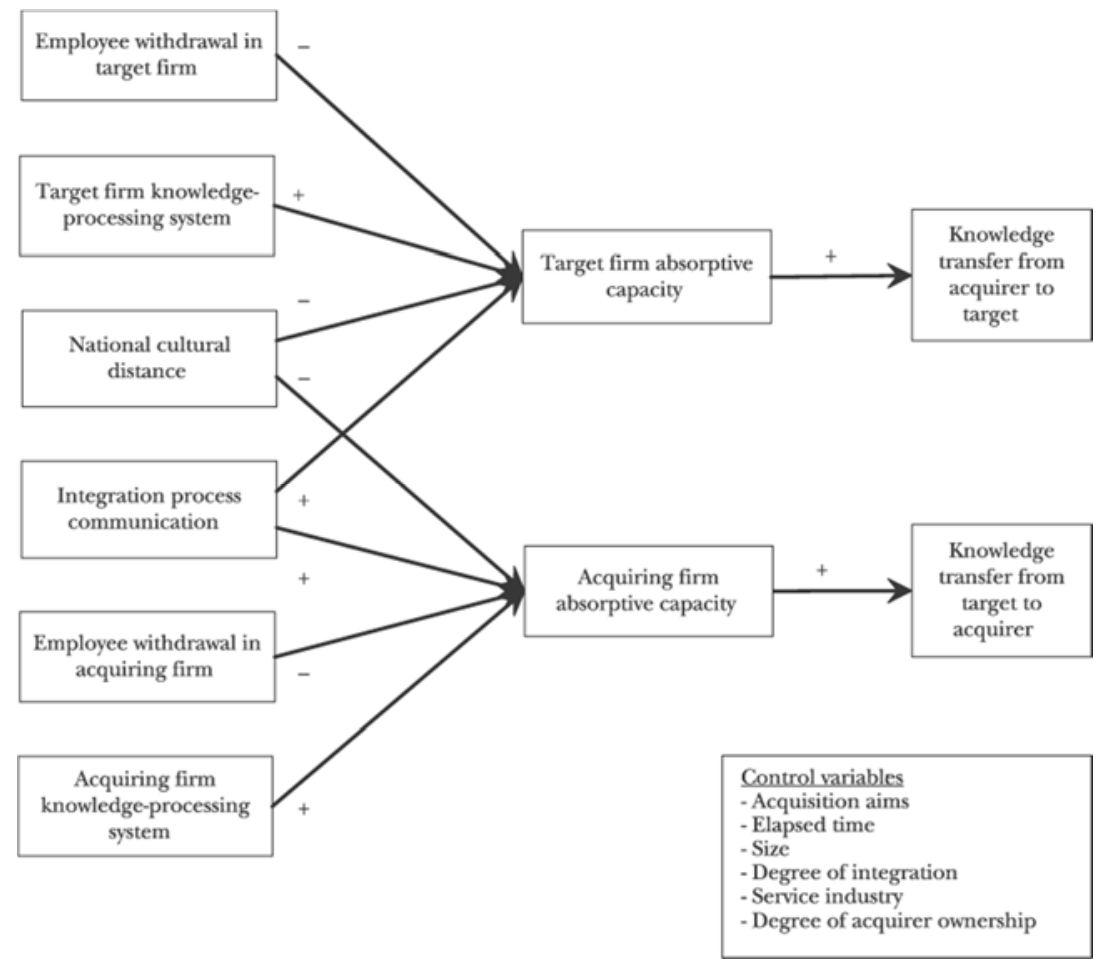


Method

Data Collection

We collected data through two surveys that were conducted in 2010 and 2011.2 The surveys included domestic and foreign acquisitions of Finnish companies, which were completed between January 2006 to September 2009 and October 2009 to September 2010, respectively. We used Finnish "Talouselämä" business magazines to identify these acquisitions.3 In order to collect data from respondents with sufficient knowledge, we contacted the CEOs of the acquiring firms by e-mail and asked them to identify respondents who had played a key role in the acquisition, including themselves, other high level managers and/or board members. We then emailed the survey to the identified respondents. We emphasized confidentiality in the cover letter, used pre-validated measures in the survey and scattered the questions in it, used complex analysis methods, and tested for common method variance effects in order to reduce the likelihood of common method variance (Chang, van Witteloostuijn, \& Eden, 2010).4

We received 123 responses, out of which 87 responses were from the acquirer and 36 from the target. We received 93 single responses and 30 multiple responses. The responses came from a total of 106 acquisitions, out of which 13 contained multiple responses. The response rate was 17 percent for the first survey round and 18 percent for the second one. In order to test for the reliability of the multiple responses, we conducted interrater reliability tests by calculating the intraclass correlation coefficients for the multiple response cases. Because the interrater reliability between the multiple answers was high in most cases, we used the multiple respondents' average scores in the data analyses (e.g., Lubatkin, Calori, Very, \& Veiga, 1998). However, we removed two cases in which the intraclass correlation coefficients were not significant, which resulted in a final sample size of 104 acquisitions. Possible nonresponse bias was examined by comparing the mean responses between the late respondents (last 25 percent) and the rest of the respondents (Armstrong \& Overton, 1977). The only difference we found in the t-tests was in the 2006-2009 dataset: late respondents were more likely to be characterized by larger national cultural differences. This suggests that it may have been easier to receive responses from culturally closer acquisitions than from culturally distant ones.5

Of the acquisition cases, 66 percent were domestic acquisitions (69 cases) and 34 percent foreign acquisitions (35 cases). All of the cases involved a Finnish acquiring company. The foreign target firms were distributed as follows: Australia (1 acquisition), Belarus (1), Canada (2), Denmark (2), Estonia (1), France (2), Germany (2), UK (1), Italy (2), Latvia (2), Lithuania (3), the Netherlands (1), Norway (2), Poland (4), Russia (1), Spain (1), Sweden (5), and United States (2). Based on the industry classifications, the acquisitions in our sample represent mostly related acquisitions (95 percent). 
Measures

Knowledge Transfer from the Acquirer to the Target Firm

Bresman et al. (1999) argue that acquisition knowledge transfer is a two-dimensional construct that consists of two types of transfers: from the acquiring firm to the target; from the target to the acquiring firm. Although some acquisition studies have not distinguished between these different types of transfers (e.g., Ahammad \& Glaister, 2011; Sarala \& Vaara, 2010; Vaara et al., 2012; Westphal \& Shaw, 2005), other studies suggest that there may be differences (Bresman et al. 1999; Capron, 1999). Therefore, in line with Capron (1999),6 we measured knowledge transfer from the acquirer to the target by asking respondents to which extent the acquirer's knowledge had been used in the target in the following areas: (1) general management expertise, (2) product innovation capabilities, (3) know-how in manufacturing processes, (4) sales and marketing expertise, (5) supplier relations, and (6) distribution and logistics expertise $(1=$ not at all to $7=$ very much).

Knowledge Transfer from the Target Firm to the Acquirer

This measure was similar to the one above, except that it related to knowledge transfer from the target to the acquirer.

\section{Acquiring Firm Absorptive Capacity}

We measured absorptive capacity by adapting the measures "recipient absorptive capacity" and "recipient motivation" by Szulanski (1996) to the acquisition context. These included questions about whether the employees (1) understood the goals of absorbing knowledge from the target company, (2) had a clear division of roles and responsibilities to absorb knowledge from the target company, (3) had the technical and managerial competence to absorb knowledge from the

target company, (4) were motivated to absorb the target's knowledge, and (5) were motivated to communicate their knowledge needs to the target company $(1=$ not at all to $7=$ very much $)$.

\section{Target Firm Absorptive Capacity}

We used the same items and scale as in the previous construct, but the questions related to the ability and motivation of target firm employees to absorb knowledge from the acquiring firm. 


\section{National Cultural Differences}

Based on the index of Kogut and Singh (1988) and the GLOBE practices scores (House, Hanges, Javidan, Dorfman, \& Gupta, 2004), we constructed a variance-adjusted sum of national cultural differences between the acquiring firm home country (Finland in all cases) and the target firm home country. This approach has been widely used in international management research (Jensen \& Szulanski, 2004; Morosini et al., 1998; Sarala \& Vaara, 2010; Vaara et al., 2012). Because we had several domestic cases in which the value of national cultural differences was zero, we conducted a logarithmic transformation to reduce the positive skewness of the variable as recommended by Tabachnick and Fidell (1996).

Employee Withdrawal in the Acquiring Firm

Drawing on employee withdrawal literature in general (Beehr \& Gupta, 1978; Kiefer, 2005) and on literature discussing the manifestations of employee withdrawal in the specific context of acquisitions (e.g. Bouwen \& Overlaet, 2001, Davy et al., 1997; Hambrick \& Cannella, 1993), we included five common forms of employee withdrawal: (1) lack of motivation, (2) increase in absenteeism, (3) decrease in productivity, (4) resistance to change, and (5) loss of key persons. We asked the respondents to rate the level of each form of employee withdrawal in the acquiring firm $(1=$ not at all to $7=$ very much $)$.

\section{Employee Withdrawal in the Target Firm}

We used the same items and scale as in the previous construct, but the respondents were asked to rate employee withdrawal in the target firm.

\section{Integration Process Communication}

The respondents indicated (1) the amount of the information communicated during the integration process to those affected by the acquisition ( $1=$ not at all to $7=$ very much), and (2) the effectiveness of the information communicated during the integration process to those involved $(1=$ not effective to $7=$ very effective) (Birkinshaw et al., 2000). In addition, adapting Schweiger and Goulet's (2005) measure of surface-level cultural learning interventions, we asked the respondents to indicate the extent to which the acquirer and target communicated about (1) each firm's history and the general values and beliefs that defined each organization, and (2) the vision and strategy of the combined organization, and the firms' roles in achieving the vision $(1=$ not at all to $7=$ very much). 


\section{Acquiring Firm Knowledge-Processing System}

Applying the measure of Zhao and Anand (2009) to the acquisition context, we measured the effectiveness of the acquiring firm's knowledge-processing system by asking respondents whether the acquiring firm had (1) maintained a low level of hierarchies and cross-function barriers in the organization structure, (2) been adaptive and flexible to structural changes aimed at improving work efficiency, (3) adopted a team-based performance appraisal and compensation system, and (4) adopted an excellent information infrastructure for employees to share information and knowledge $(1=$ strongly disagree to $7=$ strongly agree $)$.

\section{Target Firm Knowledge-Processing System}

We used the same items and scale as in the previous construct, but measured knowledgeprocessing system in the target firm.

\section{Control Variables}

Acquisition Aims

An explicit aim to access knowledge may be associated with greater levels of knowledge transfer. Hence, we controlled for the importance of obtaining the target's knowledge among different acquisition motives. We asked the respondents to rate the importance of the following acquisition motives: obtaining the target's technological knowledge (patents, R\&D, or other technological knowledge) $(1=$ not important to $7=$ very important $)$, and obtaining the target's nontechnological knowledge (sales, management etc.) $(1=$ not important to $7=$ very important). We controlled for the importance of both motives separately because they were not mutually exclusive.

In addition, there may be more scope for knowledge transfer in related acquisitions (Haspeslagh \& Jemison, 1991). Hence, we included a variable that measured the extent to which the acquisition was motivated by expanding into a related business $(1=$ not important to $7=$ very important).

Elapsed Time 
Elapsed time can impact acquisition knowledge transfer by influencing how the learning relationship develops between the acquisition partners (Bresman et al., 1999). Hence, we controlled for the number of years that had passed after the acquisition (1 to 4 years).

Size

Larger acquisitions may be more difficult to manage (Ranft \& Lord, 2002). Therefore, we controlled for the size of the acquisition based on the target firm's net sales (in millions of EUR) at the time of the acquisition.

\section{Degree of Integration}

The degree of integration may affect the amount of knowledge that is transferred (Haspeslagh \& Jemison, 1991). We included four questions concerning the current degree of integration between the companies in the following operations: (1) management and control, (2) sales and marketing, (3) production, and (4) R\&D ( $1=$ no integration to $7=$ total integration).

\section{Industry}

We used a binary variable to control for whether an acquisition was conducted in the service industry (coded as 1) or another industry (coded as 0 ). Knowledge transfer may be more difficult in service industries because employees depend more on their personal knowledge to succeed in this industry, and employees may thus be more protective of their knowledge (Empson, 2001).

\section{Ownership}

Previous research suggests that a greater level of ownership may facilitate knowledge related activities (Cantwell \& Narula, 2001). Hence, we controlled for the acquiring firm's ownership percentage of the target firm's shares after the acquisition. This variable always exceeded 50 percent, because our sample only included majority ownership cases.

\section{Results}

To test our multilevel model, we used the partial least squares (PLS) analysis method with the SmartPLS program (Ringle, Wende, \& Will, 2005). We chose PLS analysis because it is better suited for estimating complex models with several latent and indicator variables than regression 
analysis (Henseler, Ringle \& Sinkovics, 2009).7 PLS analysis consists of two steps: first, the measurement model is used to assess the reliability and validity of the measures; then, the structural model is used to test the hypothesized relationships (Henseler et al., 2009).

\section{Results of the Measurement Model}

To determine validity and reliability of the measures, we followed the recommendations of previous studies on the use of structural equation modeling in general (Fornell and Larcker, 1981; Shook, Ketchen, Hult, \& Kacmar, 2004) and of PLS in specific (Henseler et al., 2009; Hulland, 1999). Accordingly, to establish convergent validity, we examined the standardized factor loadings of each indicator in the measurement model (Shook et al., 2004). The standardized factor loadings in our model were all greater than 0.40 , which is commonly used as a rule in social sciences for retaining measurement items (Henseler et al., 2009; Hulland, 1999). We used the average variance extracted as an additional criterion of convergent validity as recommended by Fornell and Larcker (1981), Henseler et al. (2009) and Shook et al. (2004). The average variance extracted exceeded the recommended value of 0.50 or was very close to the limit (target firm knowledge-processing system: 0.488). Discriminant validity was established by verifying that the square root of average variance exceeded all corresponding correlations (Fornell \& Larcker, 1981; Henseler et al., 2009; Shook et al., 2004) (see Table 2). Also, discriminant validity was further supported by the fact that all items loaded highest on their respective constructs (Henseler et al., 2009).

The recommended method of assessing reliability in structural equal modeling in general (Fornell \& Larcker, 1981; Shook et al., 2004) and in PLS in specific (Henseler et al., 2009) is composite reliability, which assesses the internal consistency of a construct and is calculated based on the standardized loadings and measurement errors of each item (for the formula, see Fornell \& Larcker, 1981, p. 45).9 The composite reliability of all our measures exceeded 0.7. The Cronbach's alpha values for our constructs exceeded the commonly used threshold of 0.7 , except for one construct (target firm knowledge processing system: 0.65). However, we considered this to be sufficient.10 A summary of the validity and reliability statistics discussed above is presented in Table 1. Descriptive statistics and correlations are reported in Table 2. 
Table 1. Assessment of multi-item constructs

\begin{tabular}{|c|c|c|c|c|}
\hline Construct & Cronbach's alpha & $\begin{array}{l}\text { Composite } \\
\text { reliability }\end{array}$ & $\begin{array}{c}\text { Average variance } \\
\text { extracted }\end{array}$ & $\begin{array}{l}\text { Range of factor } \\
\text { loadings }\end{array}$ \\
\hline Knowledge transfer from acquirer to target & 0.85 & 0.89 & 0.56 & $0.64-0.84$ \\
\hline Knowledge transfer from target to acquirer & 0.83 & 0.87 & 0.54 & $0.68-0.81$ \\
\hline Acquiring firm absorptive capacity & 0.90 & 0.93 & 0.72 & $0.76-0.90$ \\
\hline Target firm absorptive capacity & 0.89 & 0.92 & 0.70 & $0.81-0.86$ \\
\hline Employee withdrawal in acquiring firm & 0.92 & 0.94 & 0.76 & $0.84-0.89$ \\
\hline Employee withdrawal in target firm & 0.85 & 0.90 & 0.64 & $0.68-0.88$ \\
\hline Integration process communication & 0.80 & 0.87 & 0.63 & $0.66-0.87$ \\
\hline Acquiring firm knowledge-processing system & 0.74 & 0.80 & 0.51 & $0.59-0.88$ \\
\hline Target firm knowledge-processing system & 0.65 & 0.79 & 0.48 & $0.64-0.74$ \\
\hline Degree of integration & 0.87 & 0.91 & 0.66 & $0.65-0.86$ \\
\hline
\end{tabular}

Table 2. Descriptive statistics and correlations

\begin{tabular}{|c|c|c|c|c|c|c|c|c|c|c|c|c|c|c|c|c|c|c|c|c|}
\hline Constructs & Mean & S.D. & 1 & 2 & 3 & 4 & 5 & 6 & 7 & 8 & 9 & 10 & 11 & 12 & 13 & 14 & 15 & 16 & 17 & 18 \\
\hline $\begin{array}{l}\text { 1. Acquisition aim: } \\
\text { expansion into a related } \\
\text { business }\end{array}$ & 3.108 & 2.032 & 1 & & & & & & & & & & & & & & & & & \\
\hline $\begin{array}{l}\text { 2. Acquisition aim: ob- } \\
\text { taining technological } \\
\text { knowledge }\end{array}$ & 4.246 & 1.794 & 0.279 & 1 & & & & & & & & & & & & & & & & \\
\hline $\begin{array}{l}\text { 3. Acquisition aim: } \\
\text { obtaining other types of } \\
\text { knowledge }\end{array}$ & 4.641 & 2.296 & 0.292 & 0.172 & 1 & & & & & & & & & & & & & & & \\
\hline 4. Elapsed time & 2.394 & 1.018 & -0.053 & -0.118 & -0.156 & 1 & & & & & & & & & & & & & & \\
\hline 5. Size & 31.058 & 76.345 & -0.034 & 0.033 & -0.127 & 0.016 & 1 & & & & & & & & & & & & & \\
\hline 6. Degree of integration & 5.338 & 1.29 & -0.08 & -0.016 & -0.067 & -0.002 & 0.038 & -0.812 & & & & & & & & & & & & \\
\hline 7. Industry & 0.481 & 0.502 & -0.156 & 0.014 & -0.098 & 0.157 & -0.116 & -0.012 & 1 & & & & & & & & & & & \\
\hline 8. Ownership & 93.678 & 13.932 & 0.263 & 0.142 & -0.037 & 0.042 & -0.032 & 0.066 & -0.133 & 1 & & & & & & & & & & \\
\hline $\begin{array}{l}\text { 9. Acquiring firm absorptive } \\
\text { capacity }\end{array}$ & 0.018 & 0.842 & 0.15 & -0.177 & 0.075 & -0.187 & 0.092 & 0.436 & -0.267 & 0.071 & -0.849 & & & & & & & & & \\
\hline $\begin{array}{l}\text { 10. Target firm absorptive } \\
\text { capacity }\end{array}$ & 0.004 & 0.848 & 0.202 & 0.004 & 0.043 & 0.016 & 0.062 & 0.402 & -0.107 & 0.021 & 0.55 & -0.837 & & & & & & & & \\
\hline $\begin{array}{l}\text { 11. National cultural } \\
\text { differences }\end{array}$ & 0.16 & 0.285 & 0.105 & 0.158 & -0.072 & 0.058 & 0.175 & -0.147 & -0.026 & 0.082 & 0.031 & 0.147 & 1 & & & & & & & \\
\hline $\begin{array}{l}\text { 12. Employee withdrawal in } \\
\text { the acquiring firm }\end{array}$ & 2.19 & 1.147 & -0.1 & 0.093 & 0.064 & 0.005 & 0.096 & -0.16 & -0.077 & -0.058 & -0.308 & -0.189 & -0.134 & -0.871 & & & & & & \\
\hline $\begin{array}{l}\text { 13. Employee withdrawal in } \\
\text { the target firm }\end{array}$ & 3.027 & 1.202 & -0.124 & 0.075 & -0.036 & 0.094 & -0.009 & -0.023 & 0.041 & 0.103 & -0.243 & -0.288 & -0.007 & 0.508 & -0.799 & & & & & \\
\hline $\begin{array}{l}\text { 14. Integration process } \\
\text { communication }\end{array}$ & 4.865 & 1.032 & 0.059 & 0.008 & 0.112 & -0.035 & 0.075 & 0.445 & -0.077 & 0.048 & 0.569 & 0.506 & 0.087 & -0.212 & -0.244 & -0.794 & & & & \\
\hline $\begin{array}{l}\text { 15. Acquiring firm knowl- } \\
\text { edge-processing system }\end{array}$ & 4.05 & 1.175 & 0.033 & -0.15 & -0.026 & 0.128 & 0.004 & -0.108 & 0.017 & 0.055 & -0.164 & -0.075 & -0.134 & 0.211 & 0.172 & -0.204 & -0.713 & & & \\
\hline $\begin{array}{l}\text { 16. Target firm knowledge- } \\
\text { processing system }\end{array}$ & 4.025 & 1.149 & 0.097 & -0.149 & 0.138 & 0.017 & 0.011 & 0.241 & -0.091 & 0.227 & 0.388 & 0.3 & 0.049 & -0.222 & -0.169 & 0.308 & 0.142 & -0.692 & & \\
\hline $\begin{array}{l}\text { 17. Knowledge transfer } \\
\text { from the acquirer to the } \\
\text { target }\end{array}$ & 4.515 & 1.353 & -0.191 & -0.145 & -0.089 & -0.085 & -0.072 & 0.547 & -0.147 & 0.001 & 0.389 & 0.426 & -0.083 & -0.131 & -0.045 & 0.595 & -0.161 & 0.067 & -0.751 & \\
\hline $\begin{array}{l}\text { 18. Knowledge transfer } \\
\text { from the target to the } \\
\text { acquirer }\end{array}$ & 3.763 & 1.337 & 0.337 & 0.457 & 0.316 & -0.147 & 0.08 & 0.123 & -0.089 & 0.147 & 0.201 & 0.317 & -0.085 & 0.12 & -0.079 & 0.235 & -0.118 & 0.043 & 0.207 & -0.734 \\
\hline
\end{tabular}

Numbers in brackets denote the square root of the average variance extracted (all constructs are reflective).

Mean values and standard deviations are based on unstandardized variables, other values are based on standardized variables. $\mathrm{N}=104$.

\section{Results of the Structural Model}


The overall strength of the structural model (Figure 2) was determined by examining the variance explained (R2), path coefficients and effect sizes (f2) (Gefen et al., 2000). The R2 scores of knowledge transfer from the acquirer to the target $(0.45)$, knowledge transfer from the target to the acquirer (0.36), acquiring firm absorptive capacity (0.36) and target firm absorptive capacity (0.32) were all acceptable (Henseler et al., 2009).

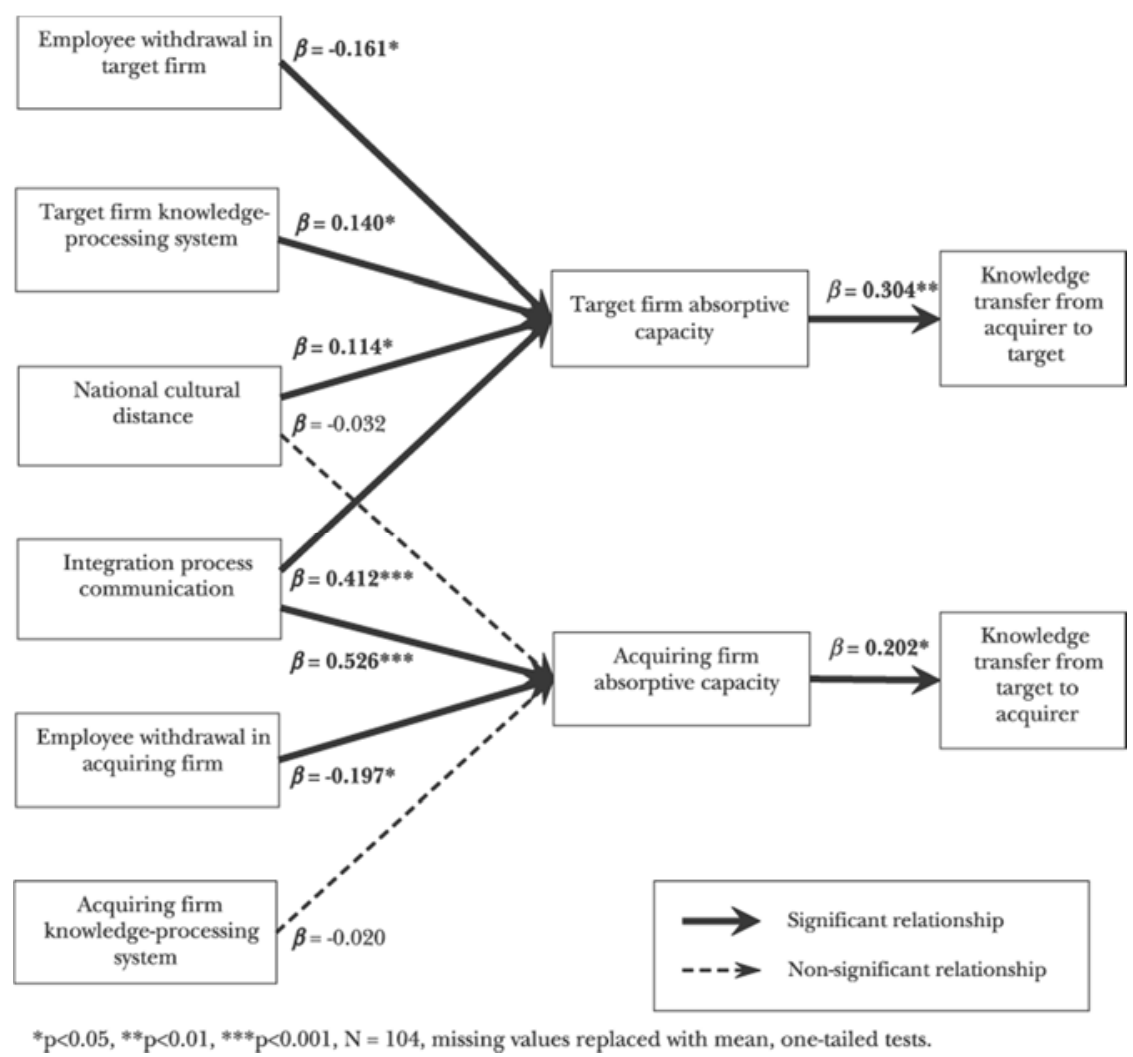

Regarding the hypotheses, we found that the absorptive capacity of the acquiring firm was positively related to knowledge transfer from the target to the acquirer $(\beta=0.202, \mathrm{p}<0.05, \mathrm{f} 2=$ 0.04). Similarly, absorptive capacity of the target firm was positively associated with knowledge transfer from the acquirer to the target $(\beta=0.304, \mathrm{p}<0.01, \mathrm{f} 2=0.13)$. Thus, Hypothesis 1 was supported. National cultural differences were positively associated with target firm absorptive capacity ( $\beta=0.114, \mathrm{p}<0.05, \mathrm{f} 2=0.02)$, which was contrary to the negative relationship proposed in Hypothesis 2. No significant relationship was found between national cultural differences and the acquirer's absorptive capacity $(\beta=-0.032, p>0.1)$. Accordingly, Hypothesis 2 was rejected. We found that employee withdrawal in the acquiring firm was negatively related to the absorptive capacity of the acquiring firm $(\beta=-0.197, \mathrm{p}<0.05, \mathrm{f} 2=0.06)$ and employee withdrawal in the target firm was negatively associated with the absorptive capacity of the target $(\beta=-0.161, \mathrm{p}<0.05, \mathrm{f} 2=0.03)$. These results supported Hypothesis 3 . Also, integration process communication was strongly and positively related to absorptive capacity in both the acquiring firm $(\beta=0.526, \mathrm{p}<0.001, \mathrm{f} 2=0.40)$ and target firm $(\beta=0.412, \mathrm{p}<0.001, \mathrm{f} 2=0.21)$, which supported Hypothesis 4. Furthermore, the strength of the target firm's knowledge-processing 
system was positively associated with the target firm's absorptive capacity $(\beta=0.140, \mathrm{p}<0.05$, $\mathrm{f} 2=0.03)$. However, the strength of the acquiring firm's knowledge-processing system was unrelated to the acquirer's absorptive capacity $(\beta=-0.020, \mathrm{p}>0.1)$. Hence, Hypothesis 5 was only supported on the target side.

Concerning control variables, the aim to obtain technological or R\&D-related knowledge from the target was negatively associated with knowledge transfer from the acquirer to the target $(\beta=$ $-0.222, p<0.01, f 2=0.06)$. In contrast, the aim to obtain other types of knowledge (e.g., related to sales or management) was positively related to knowledge transfer from the target to the acquirer $(\beta=0.409, \mathrm{p}<0.001, \mathrm{f} 2=0.18)$. The aim to expand to a related business was positively associated with knowledge transfer from the target to the acquirer $(\beta=0.206, \mathrm{p}<0.05, \mathrm{f} 2=$ $0.06)$. Furthermore, size of the target firm $(\beta=-0.131, \mathrm{p}<0.1, \mathrm{f} 2=0.03)$ and service industry $(\beta$ $=-0.146, \mathrm{p}<0.05, \mathrm{f} 2=0.03$ ) were negatively related to knowledge transfer from the acquirer to the target. Finally, the achieved level of integration was positively associated with knowledge transfer from the acquirer to the target $(\beta=0.405, \mathrm{p}<0.001, \mathrm{f} 2=0.22)$. Other relationships regarding control variables were nonsignificant.

\section{Discussion}

The aim of this study was to develop and test a model on the role of absorptive capacity in acquisitions. More specifically, drawing on acquisition and absorptive capacity literatures, we addressed important, yet underexplored areas and tested them in the context of domestic and foreign acquisitions conducted by Finnish acquirers. To reflect on our results, we established a positive relationship between the absorptive capacity of the recipient firm and knowledge transfer, both in terms of knowledge transfer from the acquirer to the target and knowledge transfer from the target to the acquirer. This finding represents a contribution to the absorptive capacity literature because it links absorptive capacity to intangible outcomes (knowledge transfer) while previous research has primarily focused on tangible outcomes (Volberda et al., 2010 , p. 942). The result also contributes to the acquisition literature by providing empirical evidence for the absorptive capacity-knowledge transfer relationship proposed theoretically by Björkman et al. (2007). Furthermore, the result supports the findings of Ahuja and Katila (2001), who controlled for the relationship between absorptive capacity (measured as patents) and technological knowledge transfer and found a positive link. Moreover, our finding extends the qualitative work of Deng (2010), who found absorptive capacity of the acquirer to be important in two Chinese acquisitions. Our study shows that not only the absorptive capacity of the acquirer but also the absorptive capacity of the target is important in acquisitions and that their antecedents may differ. Our quantitative approach also allows for generalizations beyond specific acquisition cases. 
In addition to examining knowledge transfer as an outcome of absorptive capacity, we examined the different antecedents of absorptive capacity, focusing on those that remain underexplored in the absorptive capacity literature (Volberda et al., 2010), but are likely to be important for acquisition dynamics. Related to contextual antecedents, contrary to our expectations of a negative relationship similar to those put forward in prior theoretical work on absorptive capacity in acquisitions (Björkman et al., 2007), we found that national cultural differences were unrelated to the absorptive capacity of the acquiring firm and positively related to the absorptive capacity of the target firm. One explanation for a positive effect on absorptive capacity could be that diverse and seemingly incompatible knowledge required target firm members to build new cognitive structures that increased creativity, depth, and breadth of knowledge absorption (Todorova \& Durisin, 2007). This type of learning may be more likely in the target because the target may be forced to adapt due to its often lower power position, while the acquirer may be less willing to engage in adaptive processes due to its often higher power position (Haspeslagh \& Jemison, 1991). Although most acquisition studies have reported a negative effect of national cultural differences, our positive result is in line with Morosini et al. (1998), Vaara and Sarala (2010), and Vaara et al. (2012) who showed that national cultural differences can improve knowledge transfer and acquisition performance.

Concerning individual level factors, our study shows that employee withdrawal reduces absorptive capacity both in the acquiring and target firms. This result contributes to the absorptive capacity literature by extending our knowledge on the effect of employee related issues on absorptive capacity (Volberda et al. 2010). It also supports prior acquisition research that has emphasized employee behavior as central to achieving other key acquisition outcomes (e.g. Ahammad \& Glaister, 2011; Cannella \& Hambrick, 1993; Fried et al., 1996; Empson, 2001; Weber et al., 2011). Whereas most previous acquisition studies have focused on negative employee reactions in the target firm (Cannella \& Hambrick, 1993; Fried et al., 1996), our findings show that acquiring firm members also manifest negative reactions that can have significant negative effects (Junni, 2011; Hogg \& Terry, 2001; Sarala, 2010), such as decreased absorptive capacity.

Furthermore, we examined the influence of organizational design factors (integration process communication and knowledge processing systems). Even though the original study of Cohen and Levinthal (1990) points to the importance of "distinctly organizational aspects" of absorptive capacity, apart from a few notable exceptions (Jansen et al., 2005; Minbaeva et al., 2003; Van den Bosch et al., 1999; Zhao \& Anand, 2009), subsequent research has largely overlooked the role of organizational design antecedents in defining absorptive capacity (Lane, Koka, \& Pathak, 
2006; Volberda et al., 2010). This is, however, important from the dynamic capability perspective that emphasizes the influence of managerial actions on absorptive capacity (Zahra \& George, 2001). In line with studies that have shown communication to contribute to knowledge processing in general (Jansen et al., 2005; Gupta \& Govindarajan, 2000; Nahapiet \& Ghoshal, 1998; Van den Bosch et al., 1999), we found that integration process communication positively influences absorptive capacity. This also supports the results of prior studies that have shown communication to be beneficial to acquisition outcomes in general (e.g., Birkinshaw et al., 2000; Haspeslagh \& Jemison, 1991).

Regarding the design of a knowledge-processing system, our results show that establishing an effective knowledge-processing system in the target firm-including for instance a flat and flexible organizational structure that supports inter-unit communication and rewards teamworksupports the target firm's absorptive capacity. This is in line with acquisition research that has emphasized certain organizational aspects, such as autonomy, particularly on the target side (Ranft \& Lord, 2002). However, the acquiring firm's knowledge-processing system did not impact the acquirer's absorptive capacity. Hence, the optimal organizational form for knowledge absorption in the acquiring firm seems to be different from the flexible structure suggested in this article and would be an interesting topic to explore in future studies.

Concerning the control variables, we found that the more important the aim to obtain technological knowledge from the target, the less knowledge transfer from the acquirer to the target, while the transfer of the target's knowledge remained unaffected. This implies that an acquisition motivated by technological knowledge transfer was not enough for knowledge transfer to take place. On the contrary, such an aim may have cautioned acquirers to limit the transfer of the acquirer's knowledge in order to protect what was considered the target's unique technological knowledge (Haspeslagh \& Jemison, 1991). We also found that the more important the aim to obtain non-technological knowledge from the target, the higher the level of knowledge transfer from the target to the acquirer, while knowledge transfer from the acquirer to the target remained unaffected. The motive to expand to a related business increased knowledge transfer from the target to the acquirer, which is in line with research suggesting that there is more scope for knowledge transfer in related acquisitions (e.g., Capron, 1999; Haspeslagh \& Jemison, 1991). Furthermore, acquiring firms transferred more knowledge when the target was small, which is in accordance with prior research suggesting that larger targets may be more difficult to manage (Ranft \& Lord, 2002). Also, we found that knowledge transfer was more difficult in the service industry. A possible theoretical explanation is that, in the service industry, the employee's technical and client knowledge may represent his/her principal source of value to the firm, which can make the employee reluctant to share his/her knowledge with others and thereby reduce knowledge transfer (Empson, 2001). Finally, we found that the achieved degree of integration 
increased knowledge transfer, but only from the acquirer to the target. This finding is in line with studies suggesting that acquirers need to put effort into integrating the target firm in order to facilitate the transfer of the acquirer's best practices (Haspeslagh and Jemison, 1991). In contrast to research which claims that acquirers may need to limit the degree of integration in order to preserve the target's knowledge base (Haspeslagh \& Jemison, 1991; Ranft \& Lord, 2002), we did not find integration to be harmful for knowledge transfer from the target, as signified by a nonsignificant, positive finding.

The limitations of this study should be taken into account when interpreting the findings. Our responses are mostly based on acquiring firm respondents and their perceptions. We argue that these high-level respondents were knowledgeable of both the acquiring and the target firms because they were actively involved in preacquisition decision making and in the integration process. Inter-rater reliability tests of cases in which we had multiple respondents showed a high level of agreement between target and acquiring firm respondents' answers. Another limitation is that our sample represents a mixture of domestic and foreign acquisitions. This is a common approach in acquisition studies (e.g., Lubatkin et al., 1998; Very, Lubatkin, Calori, \& Veiga, 1997). Ideally, we would have obtained a balanced sample with an equal distribution of foreign and domestic cases. However, the sample distribution reflects the prevalence of domestic acquisitions even if foreign acquisitions are steadily gaining in popularity. We believe that the amount of foreign cases in our sample (34 percent) is sufficient for drawing conclusions about the influence of national cultural differences. However, it would be interesting to validate our model with a larger sample of foreign acquisitions. Our study also has a limited ability to draw causal relationships because of cross-sectional data. Future research could apply a longitudinal method to examine how absorptive capacity and knowledge transfer evolve over time. Furthermore, our results are based mainly on related acquisitions. We think that this is in line with the prevalence of related growth motives in contemporary acquisitions. However, it is possible that the results would differ if we had focused on unrelated acquisitions. Finally, our results stem from the context of Finland - a small, open economy. While we consider this as a contribution to the international management literature because it focuses attention to the acquisition dynamics in non-US contexts, it is possible that the results would differ in other contexts. For instance, it is possible that the Finnish companies are in general considered less threatening than multinationals from larger countries, which could partially explain, for instance, the finding that national cultural differences had a positive, instead of negative, effect on target firm absorptive capacity. Additionally, we focused on exploring the absorptive capacity of the knowledge receiver. Future studies should consider examining also the role of the knowledge sender in line with the concept of disseminative capacity (Minbaeva, 2007). Finally, we examined integration process communication more at the "surface" level. Considering how important we found communication to be for absorptive capacity, future studies should also 
examine the influence of "deeper" forms of communication in line with the model of Schweiger and Goulet (2005).

The findings of our study have important implications for international managers. Our results imply that absorptive capacity is central to acquisition outcomes in terms of increased knowledge transfer. We propose that managers should support absorptive capacities in the acquiring and target firms during postacquisition integration by effective and efficient integration process communication that not only focuses on day to day practical aspects, but also relates to communicating strategic aspects, such as the acquisition strategy and vision (Schweiger \& Goulet, 2005). Communication is likely to be particularly important in foreign acquisitions in order to lower any language and communication barriers, and initial distrust towards foreign acquirers. Our study also emphasizes the importance of establishing a knowledge-processing system in the target firm, which is based on extensive interunit communication and teamwork, and is supported by an information infrastructure. In addition, it is important to increase employee retention (Ahammad \& Glaister, 2011) and to address all different types of employee withdrawal because "milder" forms of employee withdrawal may be critical indicators of subsequent employee turnover (Kiefer, 2005). This is particularly important when the knowledge that the employees possess is tacit and embedded (Ranft \& Lord, 2002). These suggestions represent a dynamic capability view of the acquisition process, according to which managers can actively influence acquisition outcomes through appropriate organizational structures, systems, and processes. However, we must add a word of caution: international managers should also consider the cultural contingency of acquisition integration. For instance, it is possible that a flat organizational structure as a part of knowledge processing system is at odds with a national culture that places a naturally high emphasis on power differences (Hofstede, 1991). Also, the alignment of the HR system with the national culture is likely to be critical when addressing employee withdrawal (Weber \& Tarba, 2010), while integration process communication should reflect national cultural styles of communication (Weber et al., 2011). Finally, we encourage international managers to view national cultural differences not as a threat, but as a potentially unique opportunity for increasing the breadth and depth of knowledge processing, particularly in the target firm.

\section{Notes}

1. This is a fully co-authored article, and the authors are listed in alphabetical order. We would like to thank the editors and the two anonymous reviewers for their insights, which have greatly improved the article. 
2. This paper is based on the same sample as Junni and Sarala (2012). The second survey was conducted in order to increase the sample size, which allowed us to build a more comprehensive model. We received 92 responses from 79 acquisitions in the first survey, and 31 responses from 27 acquisitions in the second survey. T-tests did not reveal any significant differences between the responses from the first and second survey round.

3. To acknowledge that minority owned deals and mergers of equals may have different dynamics, we focused only on majority owned acquisitions in which the acquirer gained an ownership share exceeding 50 percent as a result of the acquisition.

4. A Harman's single factor test was conducted to find out whether the data suffered from common method bias. The results of the exploratory, unrotated principal component analysis indicated the absence of a serious bias because more than one factor emerged from the factor analysis and the first and second factors explained low levels of variance: 21 percent and 32 percent (Podsakoff \& Organ, 1986).

5. However, the effect was not found in the 2009-2011 dataset, which reduces the likelihood of a systematic bias in the data collection.

6. We chose the measure of Capron (1999) because it had already been applied to the acquisition context and had been shown to have sufficient validity and reliability in prior research. The measure is comparable to those used by, for instance, Gupta and Govindarajan (2000), Minbaeva (2007), and Minbaeva et al. (2003) in the broader knowledge transfer literature.

7. Furthermore, the risks of biases and inconsistent parameter estimates in the equations are reduced because PLS takes all path coefficients and item loadings into account simultaneously (White, Varadarajan, \& Dacin, 2003). PLS is also more accurate for smaller sample sizes than other types of structural equation modeling techniques (Gefen, Straub, \& Boudreau, 2000).

8. Because this was very close to the recommended limit of 0.5 and the construct had been validated in prior studies (Zhao \& Anand, 2009), we deemed this to be sufficient. 
9. This is analogous to Cronbach's alpha, except that Cronbach's alpha assumes equal reliability of all indicators, whereas in PLS the indicators are prioritized according to their reliability. For this reason, composite reliability is recommended over Cronbach's alpha for structural equation (Shook et al., 2004) and PLS modeling (Henseler et al., 2009).

10. We maintain that 0.65 was reasonably close to the threshold of 0.7 , especially considering that some studies have suggested a cut-off value of 0.6 instead of 0.7 (e.g. Henseler et al., 2009) corresponding to many studies including constructs with a Cronbach's alpha between 0.6 and 0.7 in their models (e.g. Minbaeva et al., 2003; Szulanski, 1996). Also, as reported above, the recommended measure of reliability in structural equation and PLS modeling, composite reliability (Fornell \& Larcker, 1981; Shook et al., 2004; Henseler et al., 2009), was above the recommended threshold of 0.7 for all constructs.

\section{Biographical Information}

Paulina Junni is an assistant professor at the Department of Strategy and Logistics in BI Norwegian Business School. Her research interests relate to strategic and sociocultural aspects of mergers and acquisitions, knowledge transfer, and absorptive capacity.

Riikka M. Sarala is assistant professor of international business at the University of North Carolina in Greensboro. Her research focuses on explaining the influence of sociocultural factors and knowledge transfer in mergers and acquisitions and in multinational corporations. Her

research has been published in journals such as the Journal of International Business Studies and Journal of Management Studies.

\section{References}

Ahammad, M. F., \& Glaister, K.W. (2011). Postacquisition management and performance of cross-border acquisitions. International Studies of Management \& Organization, 41(3), 59-75.

Ahammad, M. F., Glaister, K. W., Weber, Y., \& Tarba, S. Y. (2012). Top management retention in cross-border acquisitions: The roles of financial incentives, acquirer's commitment and autonomy. European Journal of International Management, 6, 458-480. 
Ahuja, G., \& Katila, R. (2001). Technological acquisitions and the innovation performance of acquiring firms: A longitudinal study. Strategic Management Journal, 22(3), 197-220.

Almor, T., Tarba, S. Y., \& Benjamini, H. (2009). Unmasking integration challenges: The case of Biogal's acquisition by Teva pharmaceutical industries. International Studies of Management \& Organization, 39(3), 33-53.

Armstrong, J. S., \& Overton, T. (1977). Estimating nonresponse bias in mail surveys. Journal of Marketing Research, 14: 396-400.

Beehr, T. A., \& Gupta, N. (1978). A note on the structure of employee withdrawal.

Organizational Behavior \& Human Performance, 21, 73-79.

Birkinshaw, J., Bresman, H., \& Håkanson, L. (2000). Managing the post-acquisition integration process: How the human integration and task integration processes interact to foster value creation. Journal of Management Studies, 37, 395-425.

Björkman, I., Stahl, G. K., \& Vaara, E. (2007). Cultural differences and capability transfer in cross-border acquisitions: The mediating roles of capability complementarity, absorptive capacity, and social integration. Journal of International Business Studies, 38(4), 658-672.

Boateng, A., Qian, W., \& Tianle, Y. (2008). Cross-border M\&As by Chinese firms: An analysis of strategic motives and performance. Thunderbird International Business Review, 50(4), 259270.

Bouwen, J. E., \& Overlaet, B. (2001). Managing continuity in a period of takeover. Journal of Management Inquiry, 10, 27-38.

Bresman, H., Birkinshaw, J., \& Nobel, R. (1999). Knowledge transfer in international acquisitions. Journal of International Business Studies, 30, 439-463.

Buono, A. F., \& Bowditch, J. L. (1989). The human side of mergers and acquisitions: Managing collisions between people, cultures, and organizations. San Francisco, CA: Jossey-Bass.

Calipha, R., Tarba, S. Y., \& Brock, D. (2010). Mergers and acquisitions: A review of phases, motives, and success factors. Advances in Mergers and Acquisitions, 9, 1-24.

Cantwell, J., \& Narula, R. (2001). The eclectic paradign in the global economy. International Journal of the Economics of Business, 8(2), 155-172.

Capron, L. (1999). The long-term performance of horizontal acquisitions. Strategic Management Journal, 20, 987-1018. 
Capron, L., Dussauge, P., \& Mitchell, W. (1998). Resource redeployment following horizontal acquisitions in Europe and North America, 1988-1992. Strategic Management Journal, 19(7), 631-661.

Cartwright, S., \& Cooper, C. L. (1993). The role of culture compatibility in successful organizational marriage. Academy of Management Executive, 7(2), 57-70.

Chang, S-J., van Witteloostuijn, A., \& Eden, L. (2010). From the editors: Common method variance in international business research. Journal of International Business Studies, 41(2), 178184.

Cohen, W. M., \& Levinthal, D. A. (1990). Absorptive capacity: A new perspective on learning and innovation. Administrative Science Quarterly, 35, 128-152.

Datta, D. K. (1991). Organizational fit and acquisition performance: Effects of post-acquisition integration. Strategic Management Journal, 12(4), 281-297.

Datta, D. K., \& Puia, G. (1995). Cross-border acquisitions: An examination of the influence of relatedness and cultural fit on shareholder value creation in U.S. acquiring firms. Management International Review, 35(4), 337-359.

Davy, J. A., Kinicki, A. J., \& Scheck, C. L. (1997). A test of job security's direct and mediated effects on withdrawal cognitions. Journal of Organizational Behavior, 18(4), 323-349.

Deng, P. (2010). What determines performance of cross-border M\&As by Chinese companies? An absorptive capacity perspective. Thunderbird International Business Review, 52(6), 509-524.

Ellis, K. M., Weber, Y., Raveh, A., \& Tarba, S. Y. (2012). Integration in large, related M\&As: Linkages between contextual factors, integration approaches and process dimension. European Journal of International Management, 6(4), 368-394.

Empson, L. (2001). Fear of exploitation and fear of contamination: Impediments to knowledge transfer in mergers between professional service firms. Human Relations, 54, 839-863.

Fornell, C., \& Larcker, D. F. (1981). Evaluating structural equation models with unobservable variables and measurement error. Journal of Marketing Research, 18, 39-50.

Fried, Y., Tiegs, R. B., Naughton, T. J., \& Ashforth, B. E. (1996). Managers' reactions to a corporate acquisition: a test of an integrative model. Journal of Organizational Behavior, 17(5), 401-427.

Gefen, D., Straub, D. W., \& Boudreau, M. (2000). Structural equation modeling and regression: Guidelines for research practice. Communications of the Association for Information Systems, $4(7), 1-77$. 
Gomes, E., Angwin, D., Weber, Y., \& Tarba, S. Y. (in press). Critical success factors through the mergers and acquisitions process: Revealing pre- and post- M\&A connections for improved performance. Thunderbird International Business Review.

Gomes, E., Weber, Y., Brown, C., \& Tarba, S. Y. (2011). Mergers, acquisitions and strategic alliances: Understanding the process. New York, NY: Palgrave MacMillan.

Gupta, A. K., \& Govindarajan, V. (2000). Knowledge flows within multinational corporations. Strategic Management Journal, 21(4), 473-496.

Hambrick, D. C., \& Cannella A. A. (1993). Relative standing: A framework for understanding departures of acquired executives. Academy of Management Journal, 36, 733-762.

Haspeslagh, P., \& Jemison, D. B. (1991). Managing acquisitions: Creating value through corporate renewal. New York, NY: Free Press.

Henseler, J., Ringle, C. M., \& Sinkovics, R. R. (2009). The use of partial least squares path modeling in international marketing. Advances in International Marketing, 20, 277-319.

Hofstede, G. (1991). Cultures and organizations: Software of the mind. London, UK: McGrawHill.

Hogg, M. A., \& Terry, D. J. (2000). Social identity and self-categorization processes in organizational contexts. Academy of Management Review, 25, 121-140.

House, R. J., Hanges, P. W., Javidan, M., Dorfman, P., \& Gupta, V. (2004). Culture, leadership, and organizations: The GLOBE study of 62 societies. Beverly Hills, CA: Sage.

Hulland, J. (1999). Use of partial least squares (PLS) in strategic management research: A review of four recent studies. Strategic Management Journal, 20(2), 195-204.

Ivancevich, J. M., Schweiger, D. M., \& Power, F. R. (1987). Strategies for managing human resources during mergers and acquisitions. Human Resource Planning, 10, 19-35.

Jansen, J. J. P., Van Den Bosch, F. A. J., \& Volberda, H. W. V. (2005). Managing potential and realized absorptive capacity: How do organizational antecedents matter? Academy of Management Journal, 48, 999-1015.

Jensen, R., \& Szulanski, G. (2004). Stickiness and the adaptation of organizational practices in cross-border knowledge transfers. Journal of International Business Studies, 35, 508-523.

Junni, P. (2011). Knowledge transfer in acquisitions: Fear of exploitation and contamination. Scandinavian Journal of Management, 27(3), 307-321. 
Junni, P., \& Sarala, R. S. (2011). Cultural ambiguity, cultural integration, and partner attractiveness as determinants of knowledge transfer: Evidence from Finnish Acquisitions. European Journal of International Management, 5(4), 346-372.

Junni, P., \& Sarala, R. S. (2012). The roles of cultural learning and collective teaching initiatives in M\&A knowledge transfer. European Journal of Cross-Cultural Competence and Management, 2(3/4), 275-298.

Kedia, B. L., \& Bhagat, R. S. (1988). Cultural constraints on transfer of technology across nations: Implications for research in international and comparative management. Academy of Management Review, 13(4), 559-571.

Keller, W. (1996). Absorptive capacity: On the creation and acquisition of technology in development. Journal of Developmental Economics, 49(1): 199-210.

Khoja, F., \& Maranville, S. (2010). How do firms nurture absorptive capacity? Journal of Managerial Issues, 22(2), 262-278.

Kiefer, T. (2005). Feeling bad: Antecedents and consequences of negative emotions in ongoing change. Journal of Organizational Behavior, 26, 875-897.

King, D. R., Dalton, D. R., Daily, C. M., \& Covin, J. G. (2004). Meta-analyses of postacquisition performance: Indications of unidentified moderators. Strategic Management Journal, 25(2), 187-200.

Kogut, B., \& Singh, H. (1988). The effect of national culture on the choice of entry mode. Journal of International Business Studies, 19(3), 411-432.

Kostova, T., \& Roth, K. (2002). Adoption of organizational practice by subsidiaries of multinational corporations: institutional and relational effects. Academy of Management Journal, 45, 215-233.

Lane, P. J., \& Lubatkin, M. (1998). Relative absorptive capacity and interorganizational learning. Strategic Management Journal, 19(5), 461-477.

Lane, P. J., Koka, B. R., \& Pathak, S. (2006). The reification of absorptive capacity: A critical review and rejuvenation of the construct. Academy of Management Review, 31, 833-863.

Lubatkin, M., Calori, R., Very, P., \& Veiga, J. F (1998). Managing mergers across borders: A two-nation exploration of a nationally bound administrative heritage. Organization Science, 9 , 670-684.

Lynch, R. (2006). International acquisition and other growth strategies: Some lessons from the food and drink industry. Thunderbird International Business Review, 48, 605-622. 
Minbaeva, D. (2007). Knowledge transfer in multinational corporations. Management International Review, 47, 567-593.

Minbaeva, D., Pedersen, T., Björkman, I., Fey, C. F., \& Park, H. J. (2003). MNC knowledge transfer, subsidiary absorptive capacity, and HRM. Journal of International Business Studies, 34, 586-599.

Morosini, P., Shane, S., \& Singh, H. (1998). National cultural distance and cross-border acquisition performance. Journal of International Business Studies, 29, 137-158.

Mowery, D., Oxley, J., \& Silverman, B. (1996). Strategic alliances and interfirm knowledge transfer. Strategic Management Journal, 17(special issue), 77-91.

Nahapiet, J., \& Ghoshal, S. (1998). Social capital, intellectual capital, and the organizational advantage. Academy of Management Review, 23(2), 242-266.

Nahavandi, A., \& Malekzadeh, A. R. (1988). Acculturation in mergers and acquisitions. Academy of Management Review, 13(1), 79-90.

Nicholls-Nixon, C. L., \& Woo, C. Y. (2003). Technology sourcing and output of established firms in a regime of encompassing technological change. Strategic Management Journal, 24, 651-666.

Olie, R. (1994). Shades of culture and institutions in international mergers. Organization Studies, 15(3), 381-405.

Podsakoff, P. M., \& Organ, D. (1986). Self-reports in organizational research: Problems and prospects. Journal of Management, 12, 531-544.

Ranft, A. L., \& Lord, M. D. (2000). Acquiring new knowledge: The role of retaining human capital in acquisitions of high-tech firms. Journal of High Technology Management Research, 11(2), 295-319.

Ranft, A. L., \& Lord, M. D. (2002). Acquiring new technologies and capabilities: A grounded model of acquisition implementation. Organization Science, 13(4), 420-441.

Ringle, C. M., Wende, S., \& Will, A. (2005). SmartPLS Version 2.0 (beta). Hamburg, Germany: University of Hamburg.

Sagie, A., Birati, A., \& Tziner, A. (2002). Assessing the costs of behavioral and psychological withdrawal: A new model and an empirical illustration. Applied Psychology, 51, 67-89.

Sarala, R. M. (2010). The impact of cultural differences and acculturation factors on postacquisition conflict. Scandinavian Journal of Management, 26, 38-56. 
Sarala, R. M., \& Vaara, E. (2010). Cultural differences, convergence, and crossvergence as explanations of knowledge transfer in international acquisitions. Journal of International Business Studies, 41, 1365-1390.

Schildt, H., Keil, T., \& Maula, M. (2012). The temporal effects of relative and firm-level absorptive capacity on interorganizational learning. Strategic Management Journal.

Schmid, S., \& Daniel, A. (2009). Telia—A Swedish-Finnish marriage after a failed Norwegian Courtship. Thunderbird International Business Review, 51(3), 297-310.

Schweiger, D. M., \& Goulet, P. K. (2005). Facilitating acquisition integration through deep-level cultural learning interventions: A longitudinal field experiment. Organization Studies, 26, $1477-$ 1499 .

Shook, C. L., Ketchen, D. J., Hult, G. T., \& Kacmar, K. M. (2004). An assessment of the use of structural equation modeling in strategic management research. Strategic Management Journal, 25(4), 397-404.

Simonin, B. (1999). Transfer of marketing know-how in international strategic alliances: An empirical investigation of the role and antecedents of knowledge ambiguity. Journal of International Business Studies, 30, 463-490.

Stahl, G. K., \& Voigt, A. (2008). Do cultural differences matter in mergers and acquisitions? A tentative model for examination. Organization Science, 19, 160-176.

Szulanski, G. (1996). Exploring internal stickiness: Impediments to the transfer of best practice within the firm. Strategic Management Journal, 17(special issue), 27-43.

Szulanski, G., Cappetta, R., \& Jensen R. J. (2004). When and how trustworthiness matters: Knowledge transfer and the moderating effect of causal ambiguity. Organization Science, 15, 600-613.

Tabachnick, B. G., \& Fidell, L. S. (1996). Using multivariate statistics. New York, NY: HarperCollins College.

Tarba, S. Y., Almor, T., \& Benyamini, H. (2012). A comparative anatomy of two cross-border acquisitions by Teva Pharmaceutical Industries. Advances in Mergers and Acquisitions, 10, 75102.

Terry, D. J., \& Callan, V. J. (1998). In-group bias in response to an organizational merger. Group Dynamics: Theory, Research, and Practice, 2(2), 67-81.

Todorova, G., \& Durisin, B. (2007). Absorptive capacity: Valuing a reconceptualization. Academy of Management Review, 32, 774-786. 
Trompenaars, F., \& Hampden-Turner, C. (1997). Riding the waves of culture. London, UK: Nicholas Brealey.

Tsai, W. (2001). Knowledge transfer in intraorganizational networks: Effects of network position and absorptive capacity on business unit innovation and performance. Academy of Management Journal, 44, 996-1004.

Vaara, E., Sarala, R., Stahl, G., \& Björkman, I. (2012). The impact of organizational and national cultural differences on social conflict and knowledge transfer in international acquisitions. Journal of Management Studies, 49, 1-27.

Van Den Bosch, F. A. J., Volberda, H. W., \& de Boer, M. (1999). Coevolution of firm absorptive capacity and knowledge environment: Organizational forms and combinative capabilities. Organization Science, 10(5), 551-568.

Van Dick, R., Ulrich, J., \& Tissington, P. A. (2006). Working under a black cloud: How to sustain organizational identification after a merger. British Journal of Management, 17(supplement), S69-S79.

Van Knippenberg, D., Van Knippenberg, B., Monden, L., \& de Lima, F. (2002). Organizational identification after a merger: A social identity perspective. British Journal of Social Psychology, 41(2), 233-252.

Van Wijk, R., Jansen, J. J. P., \& Lyles, M. A. (2008). Inter- and intra-organizational knowledge transfer: A meta-analytic review and assessment of its antecedents and consequences. Journal of Management Studies, 45, 830-853.

Very, P., Lubatkin, M., Calori, R., \& Veiga, J. (1997). Relative standing and the performance of recently acquired European firms. Strategic Management Journal, 18, 593-614.

Volberda, H. W., Foss, N. J., \& Lyles, M. A. (2010). Absorbing the concept of absorptive capacity: How to realize its potential in the organization field. Organization Science, 21, 931951.

Weber, Y. (1996). Corporate cultural fit and performance in mergers and acquisitions. Human Relations, 49(9), 1181-1202.

Weber, Y., \& Fried, Y. (2011). The dynamic of employees' reactions during postmerger integration process. Human Resource Management, 50, 777-781.

Weber, Y., Rachman-Moore, D., \& Tarba, S. Y. (2011). HR practices during post-merger conflict and merger performance. International Journal of Cross Cultural Management, 12, 7399. 
Weber, Y., Shenkar, O., \& Raveh, A. (1996). National and corporate cultural fit in mergers/acquisitions: An exploratory study. Management Science, 42, 1215-1227.

Weber, Y., \& Tarba, S. Y. (2010). Human resource practices and performance of mergers and acquisitions in Israel. Human Resource Management Review, 20(3), 203-211.

Weber, Y., \& Tarba, S. Y. (2011). Exploring integration approach in related mergers: Postmerger integration in the high-tech industry. International Journal of Organizational Analysis, 19(3), 202-221.

Weber, Y., \& Tarba, S. Y. (2012). Mergers and acquisitions process: The use of corporate culture analysis. Cross-Cultural Management, 19(3), 288-303.

Weber, Y., Tarba, S. Y., \& Bachar, Z. R. (2010). The effects of culture clash on international mergers in the high tech industry. World Review of Entrepreneurship, 8, 103-118.

Weber, Y., Tarba, S. Y., \& Reichel, A. (2009). International mergers and acquisition performance revisited - the role of cultural distance and post-acquisition integration approach. Advances in Mergers and Acquisitions, 8, 1-17.

Weber, Y., Tarba, S. Y., \& Reichel, A. (2011). A model of the influence of culture on integration approaches and international mergers and acquisitions performance. International Studies of Management \& Organization, 41(3), 10-28.

Weber, Y., Tarba, S. Y., \& Rozen-Bachar, Z. (2011). Mergers and acquisitions performance paradox: The mediating role of integration approach. European Journal of International Management. 5(4), 373-393.

Weber, Y., Tarba, S. Y., Stahl, G. K., \& Rozen-Bachar, Z. (in press). Integration ingenuity of international mergers and acquisitions: Test of a new paradigm. In Y. Weber (Ed.), Handbook of Research on Mergers and Acquisitions. Cheltenham, UK: Edward Elgar.

Westphal, T., \& Shaw, V. (2005). Knowledge transfers in acquisitions: An exploratory study and model. Management International Review, 45(2), 75-100.

White, J. C, Varadarajan, P. R., \& Dacin, P. A. (2003). Market situation interpretation and response: The role of cognitive style, organizational culture, and information use. Journal of Marketing, 67(4), 63-79.

Zahra, S. A., \& George, G. (2002). Absorptive capacity: A review, reconceptualization, and extension. Academy of Management Review, 27(2), 185-203.

Zhao, Z. J., \& Anand, J. (2009). A multilevel perspective on knowledge transfer: Evidence from the Chinese automotive industry. Strategic Management Journal, 30, 959-983. 
Zollo, M., \& Meier, D. (2008). What is M\&A performance? Academy of Management Perspectives, 22(3), 55-77. 